\title{
Red deer Cervus elephus vigilance behaviour differs with habitat and type of human disturbance
}

Author(s): Sevvandi Jayakody, Angela M. Sibbald, Iain J. Gordon, and Xavier Lambin

Source: Wildlife Biology, 14(1):81-91.

Published By: Nordic Board for Wildlife Research

DOI: http://dx.doi.org/10.2981/0909-6396(2008)14[81:RDCEVB]2.0.CO;2

URL: http://www.bioone.org/doi/full/10.2981/0909-6396\%282008\%2914\%5B81\%3ARDCEVB

\%5D2.0.CO\%3B2

BioOne (www.bioone.org) is a nonprofit, online aggregation of core research in the biological, ecological, and environmental sciences. BioOne provides a sustainable online platform for over 170 journals and books published by nonprofit societies, associations, museums, institutions, and presses.

Your use of this PDF, the BioOne Web site, and all posted and associated content indicates your acceptance of BioOne's Terms of Use, available at www.bioone.org/page/terms_of_use.

Usage of BioOne content is strictly limited to personal, educational, and non-commercial use. Commercial inquiries or rights and permissions requests should be directed to the individual publisher as copyright holder. 


\title{
Red deer Cervus elephus vigilance behaviour differs with habitat and type of human disturbance
}

\author{
Sevvandi Jayakody, Angela M. Sibbald, Iain J. Gordon \& Xavier Lambin
}

Jayakody, S., Sibbald, A.M., Gordon, I.J. \& Lambin, X. 2008: Red deer Cervus elaphus vigilance behaviour differs with habitat and type of human disturbance. - Wild1. Biol. 14: 81-91

Red deer Cervus elaphus, even in wilderness areas, are increasingly exposed to disturbance from human recreation as well as hunting, and it has been suggested that both types of disturbance may be perceived as a predation risk. We studied the vigilance behaviour of red deer in the Scottish Highlands, in sites with traditionally high numbers of visitors ('disturbed') and sites with relatively few visitors ('less-disturbed') during the main recreational season (spring and summer), and in their mating grounds during the hunting season (autumn and winter). We carried out direct observations, using scan sampling at 3-minute intervals for 1-hour periods, and recorded the number of animals in each group that were vigilant and their mode of vigilance. During the recreational season, in both the disturbed and less-disturbed sites, data were collected in habitats with different levels of cover (grassland, heather and woodland). The percentage of animals that were vigilant was higher in disturbed than in less-disturbed sites, and higher in disturbed grassland (poor cover) and heather (intermediate cover) than in disturbed woodland (good cover). The majority of the vigilant animals in disturbed heather and woodland habitats and in all the less-disturbed habitats were standing. In disturbed grassland, however, lying was the main posture whilst vigilant. In both disturbed grassland and heather, the percentage of vigilant animals that were moving was higher than in woodland or the less-disturbed habitats. In disturbed sites, the deer were more likely to be aggregated when vigilance levels were high. During the hunting season, the overall level of vigilance was higher than at any sites during the recreational season, and the majority of vigilant animals were moving. We conclude that red deer respond to disturbance from human recreational activities by increasing their level of vigilance, but that the nature of their response varies with the level of cover available. We suggest that red deer may lie down when keeping vigil in grasslands, because lying animals are less conspicuous and the low cover will still allow animals to scan their surroundings. We conclude that, although they respond to both types of disturbance by increasing vigilance, red deer perceive human recreation as a less acute threat than hunting.

Key words: behaviour, Cervus elaphus, human disturbance, hunting, predation risk, recreation, red deer, vigilance 
Sevvandi Jayakody*, Macaulay Institute, Craigiebuckler, Aberdeen, AB15 8QH, UK and School of Biological Science, University of Aberdeen, Tillydrone Avenue, Aberdeen, AB24 2TZ, UK - e-mail: s.jayakody@, macaulay.ac.uk

Angela M. Sibbald, Macaulay Institute, Craigiebuckler, Aberdeen, AB15 8QH,UK-e-mail: angela.sibbald@macaulay.ac.uk

Iain J. Gordon, Sustainable Ecosystems, CSIRO-Davies Laboratory, PMBPO Aitkenvale, Qld 4814, Australia-e-mail: iain.gordon@csiro.au Xavier Lambin, School of Biological Science, University of Aberdeen, Tillydrone Avenue, Aberdeen, AB24 2TZ, UK-e-mail: x.lambin@abdn.ac.uk

Present address: Faculty of Fisheries, Livestock and Nutrition, Wayamba University of Sri Lanka, Makandura, Gonawila, Sri Lanka.

Corresponding author: Angela M. Sibbald

Received 11 April 2006, accepted 28 August 2006

Associate Editor: Atle Mysterud

Human disturbance to wildlife species occurs as a result of hunting (Kilgo et al. 1998, Janis \& Clark 2002), but also as a result of recreational activities (Hamr 1988, Nellemann et al. 2000). When animals are disturbed by predators they need to adjust their habitat selection rules, making a trade-off between 'fitness-enhancing' and 'survival-enhancing' activities (Lima \& Dill 1990) and behaving in a way that minimises the ratio of mortality risk to net energy intake and the effects of stress (Lima 1998). Animals adopt a diverse set of behaviours to avoid predators and enhance survival (Caro et al. 2004), with vigilance being one of the most frequently studied (McNamara \& Houston 1992, Lima 1998). The 'humancaused predation risk' hypothesis states that animals also perceive disturbance from activities such as human recreation as a predation risk (Frid \& Dill 2002). Indeed, studies of the effects of human recreational disturbance on animal behaviour have demonstrated similar impacts to those of predation, such as decreased breeding success in some bird species (Piatt et al. 1990, Giese 1996) and avoidance of energetically profitable, but disturbed, habitats in mammals, (e.g. chamois Rupicapra rupicapra (Gander \& Ingold 1997) and pygmy marmosets Callithrix pygmaea (de la Torre et al. 2000)). Several studies have also suggested that an animal's overall assessment of habitat quality takes disturbance into account by paying attention to the amount of cover providing protection against predation (Dill \& Houtman 1989, Bonenfant \& Kramer 1996).

Although it is argued that recreation is analogous to predation and capable of initiating similar 82 behavioural responses, empirical evidence is scarce, as most studies have concentrated on either the effects of disturbance (reviews in Frid \& Dill 2002) or the effects of predation (reviews in Lima 1998). Nonetheless, it has been shown that both predation and disturbance elicit similar behaviours such as increased vigilance and the formation of larger groups (Lima \& Dill 1990, Roberts 1996, Papouchis et al. 2001, Fernandez-Juricic \& Schroeder 2003). However, in most cases, the study species were exposed to natural predators as well as recreational disturbance, making it impossible to evaluate the response to either type of disturbance independently.

Due to the extinction of their natural predators, red deer Cervus elaphus in the Scottish Highlands face predation only by humans, which traditionally takes place during autumn (for males) and winter (for females) in the form of hunting by stalking, where small numbers of people approach silently on foot and individual animals are shot from some distance away by expert marksmen. However, Scottish deer are also increasingly exposed to disturbance from recreational activities, such as hillwalking, cycling and mountaineering (Staines \& Scott 1994), which peaks between late spring and late summer. Red deer in the Scottish Highlands therefore provide an opportunity for studying the responses to each type of disturbance independently. By observing animals living and feeding in both disturbed and undisturbed areas during the recreational season, we tested the hypotheses that disturbance increases vigilance in red deer and that the response varies with habitat, depending on the level of cover 
provided. Although a direct comparison of the effects of recreational disturbance and predation at the same time of year was not possible, the vigilance behaviour of deer in the recreational season was compared with vigilance behaviour during the hunting season, in order to test the human-caused predation risk hypothesis.

\section{Material and methods}

\section{Study area}

We conducted observations of red deer behaviour in the Eastern Grampian Mountains of Scotland, within an area stretching from latitude $56^{\circ} 55^{\prime} \mathrm{N}$ to $57^{\circ} 03^{\prime} \mathrm{N}$ and from longitude $3^{\circ} 08^{\prime} \mathrm{W}$ to $3^{\circ} 23^{\prime} \mathrm{W}$. The area consists of submontane vegetation and heather moorland, which are the dominant vegetation types found in the area, with native woodland, grassland and wetland covering most of the lower altitude areas (Gimingham 2002).

Within the study area, sites with different levels of disturbance ('disturbed' and 'less-disturbed') were identified from a combination of anecdotal information, historical data from local people counters, and reconnaissance surveys carried out to determine visitor flow within the selected sites. The sites which were designated as disturbed were all within $500 \mathrm{~m}$ or so of established walking tracks, in an area that is popular with visitors for its amenity value and as an access route into the mountains for hillwalkers and rock climbers. Automatic counting equipment situated beside the main track in this area recorded an average of 264 visitors per day, with 441 per day recorded over the summer months (June-August), during the three years prior to our study (G. Jones, unpubl. data). The sites which were designated as less-disturbed tended to be on higher ground and further away from the tracks, and generally received $<10$ visitors per day (G. Jones, pers. comm.).

\section{Data collection}

We collected data during the main recreational season (spring-summer) and the hunting season (autumn-winter). During the recreational season, at each disturbed site, we collected data in three habitats: grassland (DG) consisting of grasses, sedges and rushes, heather moorland (DH) consisting mainly of evergreen dwarf-shrub heather Calluna vulgaris and woodland (DW) dominated by Scots pine Pinus sylvestris. At each less-disturbed site, we collected data in mixed grass/heather habitats (LDGH) where grass and heather communities were intermingled due to the higher altitude, and in woodland (LDW). Hereafter, these five different combinations of disturbance level and habitat are referred to as 'habitat types'. During the hunting season, we only collected data from mixed grass/heather habitats in the less-disturbed sites as the deer congregated there for breeding.

We visited each site approximately once a week and behaviour data were collected between 10:00 and 17:00 hours on each occasion. We collected data both on weekdays and at weekends and carried out observations on male (stag), female (hind) and mixed groups, with a mean size of $32(\mathrm{SD}=29.5)$ individuals. As it was not possible to predict when or where animals would be available for observation, data were collected from whichever groups were present during expeditions to the observation sites and this necessarily resulted in unbalanced numbers of observations. However, we collected data from at least six different 'patches' within each habitat type to control for variation at the level of patch. No deer group was observed twice on the same day, unless they joined with other deer to form a new group in a new habitat. As it was not possible to identify individual animals, the frequency with which animals were resampled is not known. A total of 96 1-hour observations were made during the recreational season, and 14 1-hour observations during the hunting season. The former were distributed across habitat types as follows: $\mathrm{DG}=27, \mathrm{DH}=15$, $\mathrm{LDGH}=38, \mathrm{DW}=6$ and $\mathrm{LDW}=10$, and the latter were all made in the LDGH habitat. Fewer observations were made in woodland than in other habitats, due to the difficulty of seeing animals in woodland and the difficulty of approaching deer through thick vegetation without disturbing them. In order to avoid conflict with hunters, none of the observations carried out during the hunting season were of individuals or groups of deer that were being hunted at the time of the observations.

We collected data by scan sampling (Lehner 1996), using hand-held binoculars $(10 \times 42)$ and a spotting scope $(20 \times 60)$. During each 1 -hour observation period, we recorded the number of animals performing each behaviour type (Table 1) every three minutes, leading to 20 observations per hour. Observations were categorised for analysis in the following way:

- site disturbance category: disturbed or lessdisturbed; 
Table 1. Behaviour categories recorded for observations made during the recreational season.

\begin{tabular}{ll}
\hline Behaviour category & Criteria \\
\hline Feeding & Either grazing or browsing while standing, moving or lying. \\
Non-vigilant moving & Slow pacing with head bent towards the ground; neck not prominent. \\
Non-vigilant lying/ruminating & Body stretched on the ground with head bent down either ruminating or resting. \\
Grooming & Cleaning of the body using hind limbs and head. \\
Vigilant standing & Standing still with either head held parallel to the body or high; neck prominent; sometimes freezing the \\
& posture with occasional ear twitching. \\
Vigilant lying & Body stretched on ground with head held high; occasional turning of head and ear twitching. \\
Vigilant moving & Rapid pacing (either brisk walking or running) with head held high and neck very prominent and ears straight. \\
Other & Any other behaviour such as fighting, feeding young, mating. \\
\hline
\end{tabular}

- distance from observer: $<100 \mathrm{~m}, 101-500 \mathrm{~m}$ and $>500 \mathrm{~m}$;

- elevation relative to footpaths: same, $100 \mathrm{~m}$ above and $>100 \mathrm{~m}$ above;

- distance from footpaths: $<250 \mathrm{~m}, 251-500 \mathrm{~m}$ and $>500 \mathrm{~m}$;

- number of people passing within $300 \mathrm{~m}$ of the group during the observations: $0,1-10,11-50$, and $>50$;

- presence or absence of dogs;

- sex of deer group: male, female and mixed;

- group size: 3-9, 10-19, 20-49 and >49;

- degree of group dispersion: aggregated, partially aggregated and dispersed.

All distances were estimated by eye. Groups were considered to be 'aggregated' if individual animals were $<2$ deer-lengths apart, and 'dispersed' if individuals were $>2$ deer-lengths apart (Tidhar 2000). 'Partially aggregated' groups had some individuals in both categories.

\section{Data analysis}

We calculated the percentage of animals in a group performing each type of behaviour (see Table 1) at each scan, and mean percentages were then calculated for each observation period. We then calculated the total percentages of animals that were vigilant or non-vigilant, by summing the percentages of animals for each behaviour type and transformed the mean percentage values into angular form for analysis. We carried out all statistical analyses using Genstat version 7.2 (Lawes Agricultural Trust 2003).

We used General Linear Models (GLM) to test for effects of the various explanatory variables on the percentage of vigilant animals, once the effects of level of disturbance and habitat were taken into account, although we only analysed the relation- ship between the degree of group dispersion and vigilance in the disturbed sites. We used two-sample t-tests to make comparisons of the percentages of animals engaged in vigilant behaviours, nonvigilant behaviours and feeding and in disturbed and less-disturbed sites during the recreational season. We also made comparisons between percentages of animals engaged in these behaviours during the recreational season and the hunting season. As we did not make observations of deer in woodland during the hunting season, we used a subset of the data for the recreational season to make comparisons between the two seasons, which excluded all observations made in woodland.

To analyse the variation in mode of vigilance, we calculated the percentages of all vigilant animals that were engaged in each type of vigilance behaviour (standing, lying or moving). Initially, mixed models with patch as a random effect were fitted using Residual Maximum Likelihood (REML) in Genstat (Lawes Agricultural Trust 2003), in order to determine whether a significant amount of variation was explained by patch. When no significant effect of patch was found, we fitted the data using GLM, with habitat type as the fixed effect and the percentage of animals performing each mode of vigilance as the response variable. We then carried out multiple comparisons of each habitat type to test whether the result for any particular habitat type was different from each of the others, using Tukey's test at the $98 \%$ probability level. For comparisons of the percentages of animals performing each mode of vigilance in the recreationally disturbed and lessdisturbed sites and during the hunting season, we used t-tests (see above).

As a second approach, we used Canonical Variate Analysis on the full set of data for the recreational season, i.e. the percentages of animals performing each of the various behavioural types 
(see Table 1), to confirm where the main differences between habitat types lay. This analysis also indicated which of the behavioural variables are most likely to have been responsible for these differences. Canonical Variate Analysis forms linear combinations of variables, while maximising between-group variance rather than between-sample variance. We used habitat type as the grouping factor and included all recorded behaviour types (see Table 1) as variables.

\section{Results}

\section{Effects of disturbance on behaviour during the recreational season}

A larger percentage of animals were vigilant in the disturbed sites than in the less-disturbed sites $(\mathrm{t}=$ $10.59, \mathrm{P}<0.001, \mathrm{df}=49$ ), with a smaller percentage performing non-vigilant behaviours $(\mathrm{t}=-4.2$, $\mathrm{P}<0.001, \mathrm{df}=81)$ or feeding $(\mathrm{t}=-2.71, \mathrm{P}=0.008$, $\mathrm{df}=94$; Fig. 1). There was no effect of the number of people walking within $300 \mathrm{~m}$ of the deer at the time of observation $\left(\mathrm{F}_{3,95}=0.16, \mathrm{P}=0.923\right)$, although there was a trend for more deer to be vigilant when dogs were present $(34.2 \pm 2.6 \%)$ than when dogs were absent $\left(13.7 \pm 2.1 \% ; F_{1,90}=7.44\right.$, $\mathrm{P}=0.073)$. There were also no effects of group size or sex, distance from observer, distance from footpath or elevation in relation to the footpath. In disturbed sites, the percentage of deer that were vigilant declined as the degree of dispersion of the herd increased $\left(\mathrm{F}_{2,47}=24.56, \mathrm{P}<0.001\right)$, with a

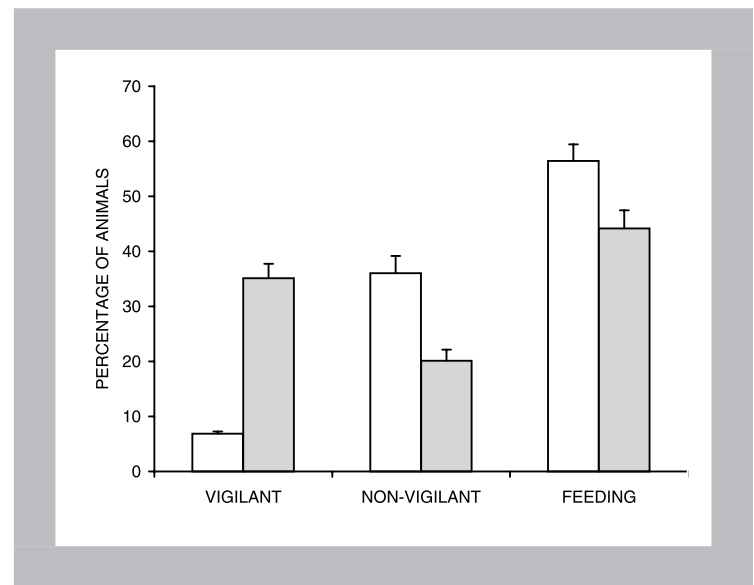

Figure 1. Mean percentage ( \pm SE) of animals performing vigilant and non-vigilant behaviours or feeding in less-disturbed sites ( $\square$ ) and in disturbed sites ( $\square$ ) during the recreational season. mean of $51.1 \pm 3.0 \%$ of animals vigilant in groups that were aggregated, $29.5 \pm 2.2 \%$ in groups that were partially aggregated and only $17.0 \pm 2.8 \%$ in groups that were dispersed.

Within the disturbed sites, there was no difference in the percentage of deer that were vigilant in grassland and heather moorland, but both were greater than the percentage vigilant in woodland $(\mathrm{DG}=40.0 \pm 3.16, \mathrm{DH}=36.0 \pm 4.50, \mathrm{DW}=10.0 \pm$ 1.88; Tukey's test: $\left.\mathrm{F}_{2,47}=8.54, \mathrm{P}<0.001\right)$. The percentages of animals moving, standing or lying when vigilant in the various habitats (Fig. 2) show that vigilant standing was the main mode of vigilance in all habitats except in disturbed grassland $\left(\mathrm{F}_{4,95}=17.82, \mathrm{P}<0.001\right)$, with the lowest percentage of animals standing when vigilant in disturbed grassland and the highest in woodland. The percentage of animals that were lying when vigilant was higher in disturbed grassland than in other habitats $\left(\mathrm{F}_{4,95}=6.80, \mathrm{P}<0.001\right)$. The percentage of animals that were moving when vigilant was higher in both disturbed grass and disturbed heather than in the other habitats $\left(\mathrm{F}_{4,95}=8.25\right.$, $\mathrm{P}<0.001)$.

The Canonical Variate Analysis indicated that the observations fell into three distinct groups: 1) all less-disturbed habitats plus disturbed woodland, 2) disturbed grassland and 3) disturbed heather (Fig. 3). The first canonical variate (CV1) separated the disturbed grassland and heather habitats from all the other habitats, whereas the second canonical variate (CV2) separated disturbed grassland

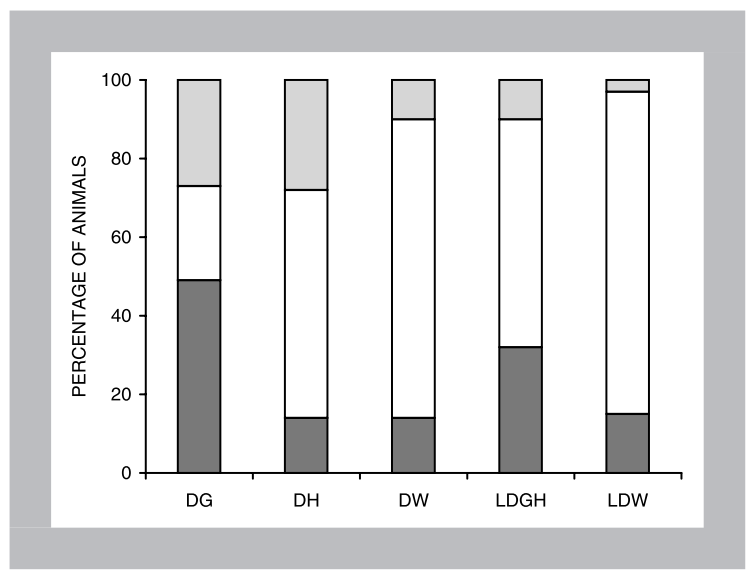

Figure 2. Mean percentages of vigilant animals performing each mode of vigilance in disturbed grassland (DG), heather (DH) and woodland (DW), and in less-disturbed grass/heather (LDGH) and woodland (LDW) during the recreational season, showing the percentage that were moving when vigilant $(\square)$, standing when vigilant $(\square)$ and lying when vigilant ( $\square$ ). 


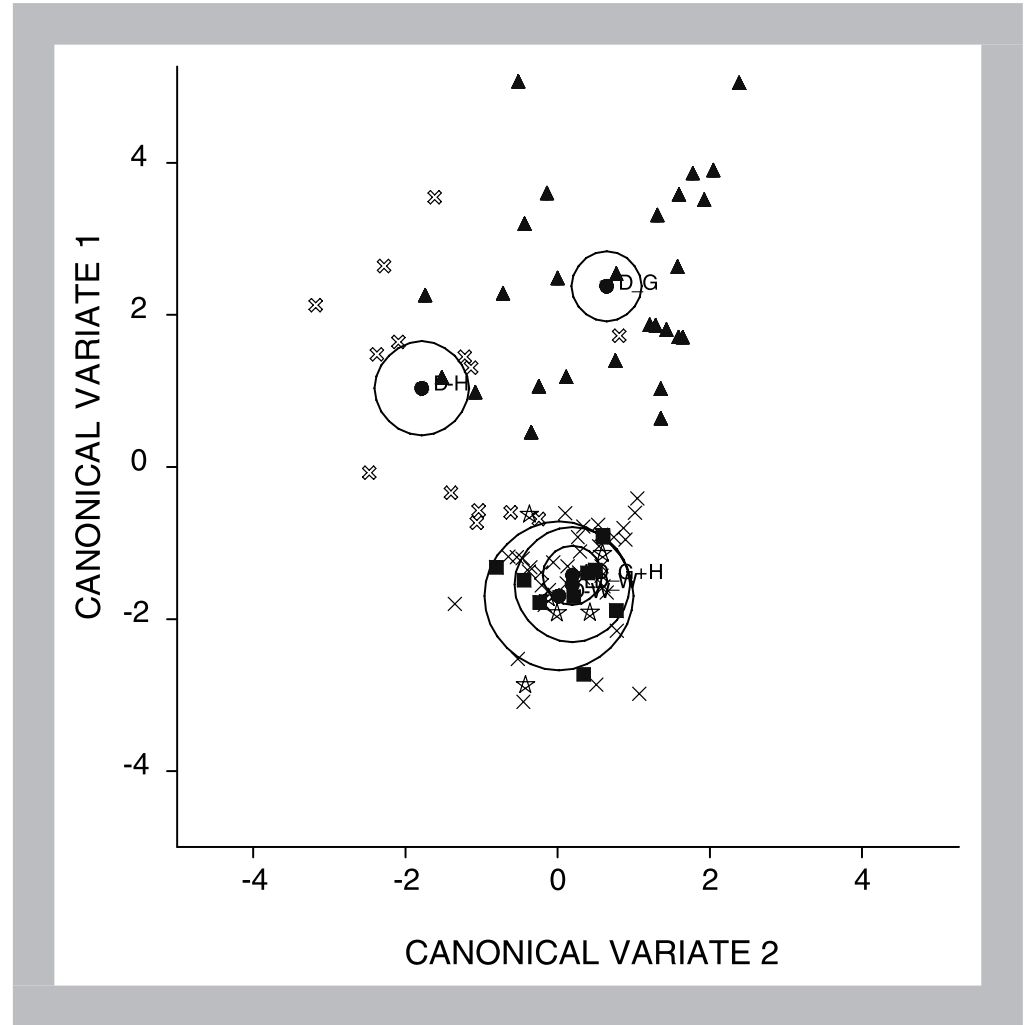

Figure 3. Canonical Variate Analysis of behaviour data for observations made during the recreational season in disturbed grassland (DG; $\boldsymbol{\Delta})$, heather $(\mathrm{DH} ; \mathrm{X})$ and woodland (DW; $₫)$, less-disturbed grass and heather (LDGH; $\mathfrak{\aleph}$ ) and woodland (LDW; $\mathbf{\square}$ ), with open circles showing $95 \%$ confidence intervals around the mean values $(\mathbf{)})$ for each habitat type.

from disturbed heather. The percentage variances explained by CV1 and CV2 were 83.61 and 13.01, respectively, and loading values for the different behaviours are shown in Table 2. For CV1, vigilant behaviours had negative loadings and non-vigilant behaviours had positive loadings, indicating that the separation between the observations in group 1 and the other groups was mainly due to differences in the balance of animals performing vigil-

Table 2. Loading values for the various behaviours in the Canonical Variate Analysis of data collected during the recreational season.

\begin{tabular}{lcc}
\hline Variate & CV1 & CV2 \\
\hline Vigilant lying & -0.135 & -0.014 \\
Vigilant moving & -0.111 & 0.014 \\
Vigilant standing & -0.073 & 0.157 \\
Other behaviours & -0.035 & 0.041 \\
Feeding & -0.028 & 0.032 \\
Non-vigilant lying/ruminating & 0.025 & 0.067 \\
Non-vigilant moving & 0.035 & -0.003 \\
Grooming & 0.105 & 0.030 \\
\hline
\end{tabular}

ant or non-vigilant behaviours. Amongst the vigilant behaviours, vigilant lying and vigilant moving accounted for most of the variation between groups, whereas grooming accounted for most of the variation in nonvigilant behaviours, as indicated by their higher absolute loading values. Similarly, vigilant standing had the largest absolute loading value for $\mathrm{CV} 2$, indicating that it was mainly differences in the percentage of animals standing that separated the observations in group 2 from those in group 3 .

\section{Comparison of behaviour dur- ing the recreation and hunting seasons}

The mean percentage of animals performing vigilant behaviours during observations in the lessdisturbed sites during the recreational season was much lower than in the same sites during the hunting season $(\mathrm{t}=10.95, \mathrm{P}<$ $0.001, \mathrm{df}=14$ ), with a higher percentage performing non-vigilant behaviours $(\mathrm{t}=3.84, \mathrm{P}<0.001, \mathrm{df}=51)$ and feed$\operatorname{ing}(t=5.21, P<0.001, d f=42 ;$ Fig. 4$)$. The mean percentage of animals that were vigilant in the

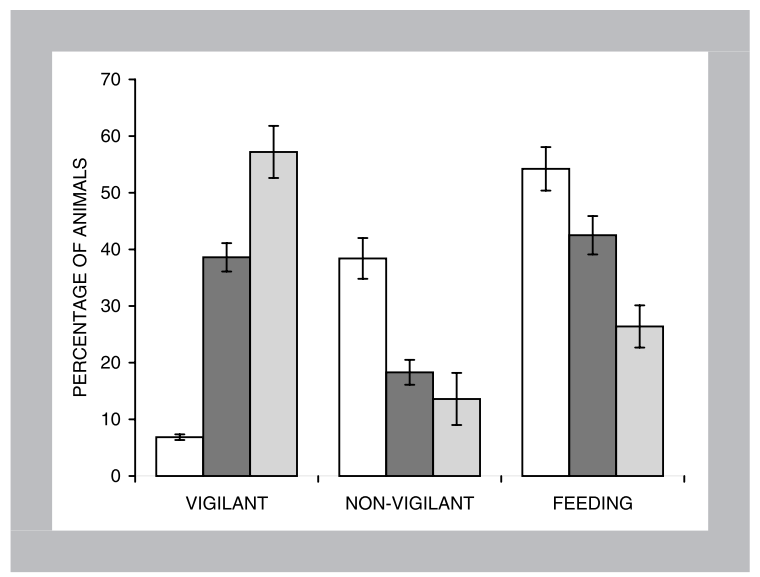

Figure 4. Mean percentage ( \pm SE) of animals performing vigilant and non-vigilant behaviours or feeding in less-disturbed sites $(\square)$, and disturbed sites during the recreational season $(\square)$ and during the hunting season $(\square)$. 
disturbed grass and heather sites during the recreational season was also lower than in the recreationally less-disturbed sites during the hunting season $(\mathrm{t}=-3.73, \mathrm{P}<0.001, \mathrm{df}=55)$ with more feeding $(\mathrm{t}=2.64, \mathrm{P}=0.011, \mathrm{df}=55)$, although there was no difference in the percentage of animals performing non-vigilant behaviours $(\mathrm{t}=1.02, \mathrm{P}=0.314$, df $=55$; see Fig. 4).

The percentage of animals standing when vigilant was greater in less-disturbed sites than in disturbed sites during the recreational season $(65.9 \mathrm{vs}$ $34.2 \%, \mathrm{t}=-4.81, \mathrm{P}<0.001, \mathrm{df}=78)$, and both were greater than the percentage standing when vigilant during the hunting season $(22.2 \pm 3.0 \%$; $\mathrm{t}=2.25, \mathrm{P}=0.028, \mathrm{df}=54$; Fig. 5). Consequently, there was a tendency for the percentage of animals lying when vigilant to be lower in less disturbed sites than in disturbed sites during the recreational season (30.7 vs $44.4 \%$; $\mathrm{t}=1.78, \mathrm{P}=0.078, \mathrm{df}=78$ ), but both were still greater than the percentage of animals lying when vigilant during the hunting season $(11.1 \pm 6.2 \% ; \mathrm{t}=2.19, \mathrm{P}=0.033, \mathrm{df}=51)$. Vigilant moving was the main mode of vigilance during the hunting season, and much more prevalent than during the recreational season, with $66.6 \pm 6.0 \%$ of animals moving when vigilant, compared to $21.4 \pm$ $3.0 \%$ in recreationally disturbed sites $(\mathrm{t}=-7.19, \mathrm{P}<$ $0.001, \mathrm{df}=55)$ and $3.7 \pm 1.2 \%$ in the less-disturbed sites $(\mathrm{t}=10.13, \mathrm{P}<0.001, \mathrm{df}=16)$.

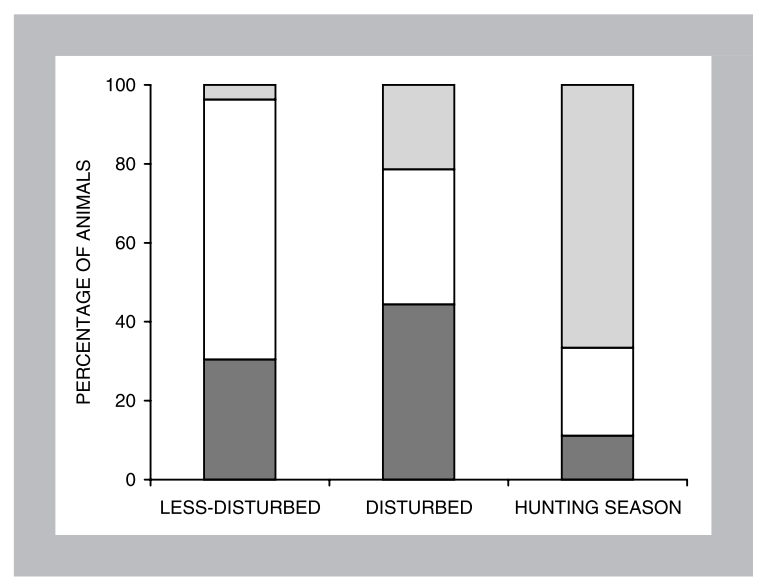

Figure 5. Mean percentages of vigilant animals performing each mode of vigilance according to level of disturbance and season, showing the percentage that were moving when vigilant $(\square)$, standing when vigilant $(\square)$ and lying when vigilant ( $\square)$.

\section{Discussion}

\section{Recreational disturbance}

During the recreational season, red deer were more vigilant in regularly disturbed habitats than in less-disturbed habitats and the animals appeared to make a clear trade-off between being vigilant and feeding, as less deer were seen to be feeding at disturbed sites. We analysed the results in relation to how far the deer were from footpaths, their elevation in relation to the footpaths and how far they were from the observer. Clearly, these variables were often confounded; for example, elevation is likely to increase with distance from paths in such terrain. However, no significant effects of any of these spatial variables were found. Surprisingly, vigilance behaviour was also unaffected by the number of people walking along the footpaths during the observations. In a previous study, red deer stags in a similar environment were affected by the numbers of people walking past at the time, and the animals were found to be approximately $100 \mathrm{~m}$ further away from footpaths on Sundays when visitor numbers were high, than on Wednesdays when they were lower (Sibbald et al.2001). However, it is possible that in the disturbed sites in our study the deer had already located themselves beyond a threshold distance at which they could tolerate people. In our study, several free-roaming dogs were observed accompanying walkers. When the dogs encroached into the deer feeding areas, they caused increased levels of vigilance and aggregation of the deer. This finding, that the deer responded to dogs more than to people on foot, is supported by similar findings for other species such as free-ranging sheep (MacArthur et al. 1979, 1982), domestic cattle (Welp et al. 2004), western snowy plovers Charadrius alexandrinus nivosus (Lafferty 2001) and sanderlings Calidris alba (Thomas et al. 2003). Although extinct in Britain today, wolves Canis lupus historically lived alongside red deer (Clutton-Brock \& Albon 1989), which could have resulted in deer evolving anti-predator defences against canid species, even though a lack of predation over time (Berger et al. 2001) and a current lack of predators (Boving \& Post 1997, Sand et al. 2006) can sometimes lead to a reduced sensitivity to predators.

There was a very clear effect of habitat on the mode of vigilance shown in the disturbed sites. The grassland habitats in our study consisted of short, 
green vegetation, and red deer were mainly lying when they were vigilant. This could be because grass provides very little cover, making it advantageous to lie down when being vigilant, as standing animals are very conspicuous in open habitats. Also, due to the openness of grassland deer can still scan the surroundings when they are lying down, which is harder to do in woodland. It could also be due to direct exposure to wind, since lying down is more energy-efficient than standing against the wind. One of the fundamental assumptions underlying most vigilance models is that animals are unable to be vigilant while feeding (Pulliam et al. 1982, McNamara \& Houston 1992). However, Lima \& Bednekoff (1999) suggested that vigilance could be of two types; overt head-up vigilance, which is high quality but energetically costly, or head-down vigilance, which is lower quality but does not prevent animals from feeding. For animals grazing with their heads down, it should be much easier to detect a change in the vigilance behaviour of a group member that is lying down than one that is standing, making it possible that vigilant lying deer are facilitating the grazers. It has been argued that an advantage of being in a group is that it allows individuals to feed while benefiting from the vigilance of others in the group (Pulliam et al. 1982, Elgar et al. 1984), although this has been disputed (Lima 1995). More deer were seen lying down while vigilant in grassland and in the mixed grass/heather habitats than in pure heather or woodland habitats, supporting the argument that this behaviour may be an adaptation for grassland.

Several studies have demonstrated the importance of refuges for reducing vigilance behaviour caused by human recreational disturbance (Frid 1997, Evans \& Day 2002). While it has been found that animals decrease their level of vigilance when they are near cover (Ikuta \& Blumstein 2003), observations of vigilance behaviour inside refuge areas are scarce. In our study, the Canonical Variate Analysis demonstrated very clearly that the level of vigilance behaviour in disturbed woodland was different from that seen in the other disturbed habitats and similar to that in the lessdisturbed sites. This is most likely to be due to the high level of cover provided by woodland, and the availability of good cover is likely to explain why vigilant animals moved very little in disturbed woodland, compared to the grass and heather habitats. The results of the Canonical Variate Analysis also demonstrated that behaviour in disturbed grassland and heather differed primarily in the percentage of animals standing when vigilant. The similar colouring of heather and red deer and the extra height of the heather plants will help to camouflage any lying animals, so that there will be less need for vigilance while lying down. Heather moorland is also found mainly on the slopes of glens and hills (Gimingham 2002) and standing red deer will be more prominent in elevated positions, making it necessary to be more vigilant.

Greater tolerance of conspecifics when forming large groups as an anti-predator defense mechanism has been well documented for encounters with real predators (Endler 1991, Cresswell 1994), as animals trade-off the risk of interference and depletion of resources for the better protection which results from moving closer together. Our results contradict the findings of some other studies which found that, when faced with real predators, levels of vigilance increased as the distance between group members increased (Lazarus 1979, Elgar et al. 1984, Poysa 1994). However, it is not possible to attribute cause and effect, and it is likely that a correlation between aggregation and vigilance will occur simply because deer react to disturbance by increasing both vigilance and their degree of aggregation.

\section{Hunting disturbance}

Observing red deer during the hunting season was more difficult than during the recreation season, hence the lower numbers of observations. This was due to the fact that the animals moved between sites more frequently and the time available for observations was shorter. It was also not possible to observe animals in recreationally disturbed areas during the hunting season. With the onset of mating, deer were found predominantly on the higher grounds that had been identified as less-disturbed sites during the recreation season, and hunting tended to be concentrated in these areas. Because of this, the observations of vigilance in deer exposed to disturbance from hunting were both temporally and spatially segregated from those of deer exposed to disturbance from recreation. However, the fact that vigilance was greatest during the hunting season, even though the deer occupied areas normally associated with low levels of disturbance from recreation, suggests that hunting produces a greater vigilance response. There appeared to be an even greater trade-off with feeding than there was during the recreational season, since even fewer deer were 
feeding during observations made in the hunting season. However, this could be due to seasonal variations in appetite, as the appetites of both stags (Kay 1978) and hinds (Milne et al. 1990) are known to decrease during the autumn. Also, red deer invest a lot of time in mating activities at that time of year (Clutton-Brock et al. 1982), so that it is not possible to estimate the precise contribution of disturbance to the overall reduction in feeding or, indeed, the increase in vigilance behaviour. In our study area, the rutting period finishes sometime during the last week of October and the first week of November (S. Blackett, pers. comm.), while the hunting season observations in our study were carried out between late October and mid-December. Over this period of time, there was a linear decline in the percentage of deer that were vigilant (slope $=0.75 \%$ per day, $\mathrm{R}^{2}=31.7, \mathrm{P}<0.05$ ), suggesting that there could have been an extra component of vigilance behaviour at the start, associated with mating. However, it was not possible to quantify the intensity of hunting activities that took place during the study, so a similar decline in hunting disturbance over this period cannot be ruled out.

For the reasons mentioned above, we could not compare the behaviour of deer during the recreational season and during the hunting season in the same habitat. However, the level of cover provided by the mixed grass/heather habitat, frequented during the hunting season, was intermediate between the grassland and heather of the recreationally disturbed sites. If the deer were similarly responsive to disturbance from recreation and hunting, we might have expected to find levels and modes of vigilance that were also intermediate. Animals are known to obtain information about predation in many ways, such as using chemical cues (Kats \& Dill 1998, Sih \& Kats 1994), alarm calls and territorial markings (Lima 1994) and even lunar cycles (Kotler et al. 1993). As hunting occurs from late summer to winter, the temporal predictability of hunting could be used by deer as a cue to alter their way of reacting to humans. It has also been shown that animals can distinguish between active and inactive predators (Dill 1974), and between predators and nonpredators that are superficially similar (Peckarsky \& Dodson 1980). Hence, the presence of people walking along the tracks during the spring and summer could be perceived as a low risk of predation and a threat of a general nature, whereas the appearance of hunters in rarely disturbed areas during the autumn and winter could be perceived as an immediate threat, resulting in escape movement.

In summary, the results of our study demonstrate that groups of red deer in the Scottish Highlands respond to disturbance from human recreational activities by increasing their level of vigilance, and the mode of vigilance behaviour is influenced by the amount of cover provided by the habitat. One of the implications of this is that off-road human recreation is not entirely compatible with viewing deer in their natural environment. However, the provision of some type of cover, particularly in the form of woodland, is likely to be beneficial if deer are to be encouraged to feed in particular areas. Although the response to recreational disturbance is analogous to the response characteristically shown by prey species to an increased predation risk, the results do not support the human-caused predation risk hypothesis, since vigilance behaviour during the hunting season involved a much larger escape component than was seen in disturbed sites during the recreational season. However, our study was carried out in an area traditionally used for recreational pursuits, and it is possible that in more remote wilderness areas, where encounters with humans are rare, deer are unable to make such a distinction between walkers and hunters.

Acknowledgements - our research was funded by the Commonwealth Scholarship Association (UK) and the Scottish Executive Environment and Rural Affairs Department. We wish to thank the staff of Balmoral and Invercauld Estates for permission to carry out observations of the deer. Thanks are also due to Russell Hooper and Roz Anderson for assistance with field observations, David Elston of Biomathematics and Statistics Scotland for expert statistical advice and to David Cope and Russell Hooper for helpful comments on an earlier version of the manuscript.

\section{References}

Berger, J., Swenson, J.E. \& Persson, I.L. 2001: Recolonizing carnivores and naive prey: Conservation lessons from Pleistocene extinctions. - Science 291: 10361339.

Bonenfant, M. \& Kramer, D.L. 1996: The influence of distance to burrow on flight initiation distance in the woodchuck, Marmota monax. - Behavioural Ecology 7: 299-303.

Boving, P.S. \& Post, E. 1997: Vigilance and foraging behaviour of female caribou in relation to predation risk. - Rangifer 17: 55-63. 
Caro, T.M., Graham, C.M., Stoner, C.J. \& Vargas, J.K. 2004: Adaptive significance of antipredator behaviour in artiodactyls. - Animal Behaviour 67: 205-228.

Clutton-Brock, T.H. \& Albon, S.D. 1989: Red deer in the highlands. - BSP Professional Publishers, Oxford, UK, pp. 13-17.

Clutton-Brock, T.H., Guinness, F.E. \& Albon, S.D. 1982: Red deer: Behaviour and ecology of two sexes. - University of Chicago Press, Chicago, USA, pp. 104-142.

Cresswell, W. 1994: Flocking is an effective antipredation strategy in redshanks, Tringa totanus. - Animal Behaviour 47: 433-442.

de la Torre, S., Snowdon, C.T. \& Bejarano, M. 2000: Effects of human activities on wild pygmy marmosets in Ecuadorian Amazonia. - Biological Conservation 94: 153-163.

Dill, L.M. 1974: The escape response of the zebra danio (Brachydanio rerio). 1. The stimulus for escape. - Animal Behaviour 22: 710-721.

Dill, L.M. \& Houtman, R. 1989: The influence of distance to refuge on flight initiation distance in the gray squirrel (Sciurus carolinensis). - Canadian Journal of Zoology 67: 233-235.

Elgar, M.A., Burren, P.J. \& Posen, M. 1984: Vigilance and perception of flock size in foraging house sparrows (Passer domesticus L.). - Behaviour 90: 215223.

Endler, J.A. 1991: Interactions between predators and prey. - In: Krebs, J.R. \& Davies, N.B. (Eds.); Behavioural Ecology, 3rd edition. Blackwell Scientific Publications, Oxford, UK, pp. 169-196.

Evans, D.M. \& Day, K.R. 2002: Hunting disturbance on a large shallow lake: the effectiveness of waterfowl refuges. - Ibis 144: 2-8.

Fernandez-Juricic, E. \& Schroeder, N. 2003: Do variations in scanning behaviour affect tolerance to human disturbance? - Applied Animal Behaviour Science 84: 219-234.

Frid, A. 1997: Vigilance by female Dall's sheep: Interactions between predation risk factors. - Animal Behaviour 53: 799-808.

Frid, A. \& Dill, L. 2002: Human-caused disturbance stimuli as a form of predation risk. - Conservation Ecology 6: Art No. 11.

Gander, H. \& Ingold, P. 1997: Reactions of male alpine chamois (Rupicapra rupicapra) to hikers, joggers and mountain bikers. - Biological Conservation 79: 107109.

Giese, M. 1996: Effects of human activity on adelie penguin. (Pygoscelis adeliae) breeding success. - Biological Conservation 75: 157-164.

Gimingham, C.H. (Ed.) 2002: The Ecology, Land Use and Conservation of the Cairngorms. - Packard Publishing Limited, West Sussex, UK, pp. 23-42.
Hamr, J. 1988: Disturbance behaviour of chamois in an Alpine tourist area of Austria. - Mountain Research Development 8: 65-73.

Ikuta, L.A. \& Blumstein, D.T. 2003: Do fences protect birds from human disturbance? - Biological Conservation 112: 447-452.

Janis, M.W. \& Clark, J.D. 2002: Responses of Florida panthers to recreational deer and hog hunting. - Journal of Wildlife Management 66: 839-848.

Kats, L.B. \& Dill, L.M. 1998: The scent of death: chemosensory assessment of predation risk by prey animals. - Ecoscience 5: 361-394.

Kay, R.N.B. 1978: Seasonal changes of appetite in deer and sheep. - A.R.C. Research Review 5: 13-15.

Kilgo, J.C., Labisky, R.F. \& Fritzen, D.E. 1998: Influences of hunting on the behaviour of White-tailed deer: implications for the conservation of Florida Panther. - Conservation Biology 12: 1359-1364.

Kotler, B.P., Brown, J.S. \& Mitchell, W.A. 1993: Environmental factors affecting patch use in 2 species of Gerbilline rodents. - Journal of Mammalogy 74: 614620.

Lafferty, K.D. 2001: Disturbance to wintering western snowy plovers. - Biological Conservation 101: 315325.

Lawes Agricultural Trust 2003: Genstat version 7.2. Rothamsted Experimental Station, UK.

Lazarus, J. 1979: The early warning function of flocking in birds: an experimental study with captive quelea. - Animal Behaviour 27: 855-865.

Lehner, P.N. 1996: Handbook of ethological methods. - Cambridge University Press, Cambridge, UK, pp. 189-209.

Lima, S.L. 1994: Collective detection of predatory attack by birds in the absence of alarm signals. - Journal of Avian Biology 25: 319-326.

Lima, S.L. 1995: Back to the basics of antipredatory vigilance - the group-size effect. - Animal Behaviour 49: 11-20.

Lima, S.L. 1998: Stress and decision making under the risk of predation; recent developments from behavioural, reproductive and ecological perspectives. - Advances in the Study of Behaviour 27: 215-290.

Lima, S.L. \& Bednekoff, P.A. 1999: Back to the basics of antipredatory vigilance: can non-vigilant animals detect attack? - Animal Behaviour 58: 537-543.

Lima, S.L. \& Dill, L.M. 1990: Behavioural decisions made under the risk of predation - a review and prospectus. - Canadian Journal of Zoology 68: 619-640.

MacArthur, R.A., Geist, V. \& Johnston, R.H. 1982: Cardiac and behavioral responses of mountain sheep to human disturbance. - Journal of Wildlife Management 46: 351-358.

MacArthur, R.A., Johnston, R.H. \& Geist, V. 1979: Factors influencing heart rate in free-ranging bighorn 
sheep: a physiological approach to the study of wildlife harassment. - Canadian Journal of Zoology 57: 20102021.

McNamara, J.M. \& Houston, A.I. 1992: Evolutionarily stable levels of vigilance as a function of group-size. - Animal Behaviour 43: 641-658.

Milne, J.A., Loudon, A.S.I., Sibbald, A.M., Curlewis, J.D. \& McNeilly, A.S. 1989: Effects of melatonin and a dopamine agonist and antagonist on seasonal changes in voluntary intake, reproductive activity and plasma concentrations of prolactin and tri-iodothyronine in red deer hinds. - Journal of Endocrinology 125: 241-249.

Nellemann, C., Jordhoy, P., Stoen, O.G. \& Strand, O. 2000: Cumulative impacts of tourist resorts on wild reindeer (Rangifer tarandus tarandus) during winter. - Arctic 53: 9-17.

Papouchis, C.M., Singer, F.J. \& Sloan, W.B. 2001: Responses of desert bighorn sheep to increased human recreation. - Journal of Wildlife Management 65: 573582.

Peckarsky, B.L. \& Dodson, S.I. 1980: Do stonefly predators influence benthic distributions in streams? - Ecology 61: 1275-1282.

Piatt, J.F., Roberts, B.D., Lidster, W.W., Wells, J.L. \& Hatch, S.A. 1990: Effects of human disturbance on breeding Least and Crested Auklets at St-Lawrenceisland, Alaska. - Auk 107: 342-350.

Poysa, H. 1994: Group foraging, distance to cover and vigilance in the teal, (Anas crecca). - Animal Behaviour 48: 921-928.

Pulliam, H.R., Pyke, G.H. \& Caraco, T. 1982: The scanning behaviour of Juncos - a game-theoretical approach. - Journal of Theoretical Biology 95: 89-103.
Roberts, G. 1996: Why individual vigilance declines as group size increases? - Animal Behaviour 51: 10771086.

Sand, H., Wikenros, C., Wabakken, P. \& Liberq, O. 2006: Cross-continental differences in patterns of predation: will naïve moose in Scandinavia ever learn? - Proceedings of the Royal Society B-Biological Sciences 273: 1421-1427.

Sibbald, A.M., Hooper, R.J., Gordon, I.J. \& Cumming, S. 2001: Using GPS to study the effect of human disturbance on the behaviour of red deer stags on a highland estate in Scotland. - In: Sibbald, A.M. \& Gordon, I.J., (Eds.); Proceedings of the conference on tracking animals with GPS. The Macaulay Institute, Aberdeen, UK, pp. 39-44.

Sih, A. \& Kats, L.B. 1994: Age, experience, and the response of streamside salamander hatchlings to chemical cues from predatory sunfish. - Ethology 96 : 253-259.

Staines, B.W. \& Scott, D. 1994: Recreation and red deer: a preliminary review of the issues. - Scottish Natural Heritage, Perth, UK, pp. 1-10.

Tidhar, D. 2000: Short-term responses of wild red deer Cervus elaphus stags to intense recreational disturbance. - M.Sc. thesis, University of Aberdeen, UK, pp. 7-10.

Thomas, K., Kvitek, R.G. \& Bretz, C. 2003: Effects of human activity on the foraging behaviour of sanderlings (Calidris alba). - Biological Conservation 109: 67-71.

Welp, T., Rushen, J., Kramer, D.L., Festa-Bianchet, M. $\&$ de Passille, A.M.B. 2004: Vigilance as a measure of fear in dairy cattle. - Applied Animal Behaviour Science 87: 1-13. 